\section{Las Prácticas para la Inclusión Social en la Facultad de Ciencias Económicas de la Universidad de Buenos Aires}

Federico Saravia

saravia@econ.uba.ar

María Victoria Álvarez

vikialvarez11@gmail.com

Docentes e integrantes de la Secretaría de Bienestar Estudiantil de la Facultad de Ciencias Económicas. Universidad de Buenos Aires, Argentina.
Integración de la docencia y la extensión /

Desafíos de gestión

RECEPCIÓN: 14/06/16

ACEPTACIÓN FINAL: 23/08/16

\section{Resumen}

Durante los últimos años, diversas iniciativas han colaborado con el estrechamiento del vínculo entre Universidad y comunidad: la Facultad de Ciencias Económicas de la Universidad de Buenos Aires (FCE-UBA), ha resignificado el concepto de extensión universitaria entendiendo, por un lado, que la relación entre la universidad y la comunidad es indisoluble y, por otro, que el vínculo entre la oferta curricular y las actividades de extensión universitaria debe construirse y desarrollarse bajo el paradigma de la Responsabilidad Social Universitaria. En este marco, se propone dar cuenta del recorrido y los desafíos planteados desde la materia "Prácticas para la Inclusión Social" (PIS) en la FCE-UBA.

\section{Resumo}

Nos últimos anos, diversas iniciativas cooperaram com o estreitamento do vínculo entre a Universidade e a Comunidade: a Facultade de Ciências Econômicas da Universidade de Buenos Aires (FCE-UBA), ressignificou o conceito de extensão universitária entendendo, por um lado, que a relação entre a universidade e a comunidade é indissolúvel e, por outro, que o vínculo entre a oferta do currículo e as atividades da extensão universitária, deve ser construído e deve desenvolverse no paradigma da Responsabilidade Social Universitária. Neste contexto, propõe-se dar conta do percurso e dos desafios apresentados pela disciplina "Práticas para a Inclusão Social" (PIS) na FCE-UBA.

Palavras-chave

- Responsabilidade Social Universitária

- Aprendizagem serviço

- Práticas para a Inclusão Social

- Sistematização

- Desafio 
1. Los orígenes y objetivos de prácticas para la inclusión social La esencia de "Prácticas para la Inclusión Social" (PIS) —su origen, móvil, razón de ser- remite a una actitud de apertura por parte de quienes somos parte de la Universidad en tanto organización, respecto de las necesidades de las comunidades en las que las organizaciones se integran (Saravia, 2010). La materia es una iniciativa de Responsabilidad Social Universitaria (RSU) en tanto se encuentra alineada con la actividad principal de la organización "Universidad Pública", fundamentalmente académica, desarrollada sobre la base de los pilares de investigación, docencia y extensión. Es una propuesta pedagógica en sintonía con uno de los más importantes aportes de la argumentación de Peter Drucker (1968) respecto de la cuestión de la responsabilidad social de las organizaciones, que es la necesidad de que ella no sea secundaria, accesoria, lateral o periférica sino fundamental desde el punto de vista de la misión de la organización (Saravia, 2009).

A partir del segundo cuatrimestre del año 2010, la materia optativa PIS se incorporó a la oferta curricular de la FCE-UBA (Resolución CD 291/10), estando abierta a la inscripción de los alumnos de las carreras de Actuario, Contador Público, Licenciatura en Administración, Licenciatura en Economía y Licenciatura en Sistemas de Información de las Organizaciones. A través de dicha implementación se asumió el desafío de integrar en una misma materia a estudiantes de las cinco carreras de la Facultad y al equipo de docentes, permitiendo así un abordaje interdisciplinario de las problemáticas que más afectan a las organizaciones y a la comunidad en su conjunto.

Desde sus orígenes, la materia recoge aquella tradición universitaria de "extensión", que junto a la "docencia" han sido dos de los pilares fundamentales de la universidad pública. Es decir, la RSU tal como la concebimos desde sus inicios - asociada a los proyectos de voluntariado, las acciones de extensión universitaria y la promoción de la metodología del aprendizaje-servicio (Tapia, 2015)_, da un nuevo paso con el nacimiento de PIS adquiriendo una mayor presencia institucional y tomando un lugar relevante en el plan de estudios de la FCE-UBA.

Desde su programa y sobre la base de la metodología del aprendizaje-servicio promueve la utilización por parte de los estudiantes de las herramientas adquiridas en el transcurso de la carrera y de la materia en el desarrollo de un trabajo de campo, el cual les permite intervenir en la realidad concreta junto con las organizaciones, involucrándose en la resolución de problemáticas específicas.

\section{al considerar a lo multidisciplinario como condición para conformar el equipo, se apuesta a la integralidad del diseño de la propuesta en respuesta a esa necesidad insatisfecha que manifiesta la organización y que el equipo detecta}

Tal como lo sintetiza Tapia (2015), la metodología del aprendizajeservicio se caracteriza por:

- Estar protagonizada fundamentalmente por los estudiantes.

- Atender solidariamente una necesidad real y sentida por la comunidad

- Estar planificada no sólo para atender a esa necesidad social, sino para mejorar la calidad de los aprendizajes.

En primer lugar, es posible decir que el aprendizaje-servicio es, por definición, una actividad de los estudiantes. Desde PIS, se busca que los estudiantes se "apropien" del proyecto, pues si no lo sienten como algo propio, difícilmente constituya una experiencia de aprendizaje-servicio de calidad. A su vez, como bien afirma Tapia (2015), se busca ofrecer un servicio concreto: no un simulacro, no una actividad que tranquilice las conciencias, no una acción ocasional, sino una respuesta acotada pero lo más eficaz posible a una problemática real.

Finalmente, la metodología aplicada en PIS apunta a que los alumnos aprendan más contenidos, desarrollen más competencias y aprendan más y mejor, complementando las ya vías tradicionales. La materia tiene como premisa que, para desarrollar las prácticas, es necesario que los alumnos estén organizados en equipos de trabajo para coordinar los esfuerzos: esta característica es clave para el éxito de las experiencias, pues un equipo de trabajo genera sinergia positiva a través de un esfuerzo coordinado. Se apela al "aprendizaje cooperativo", no solo por la complejidad del abordaje de la problemática y la necesidad de enriquecer la labor, sino también por el carácter interdisciplinar del trabajo en equipo propuesto. La existencia de una interdependencia de las contribuciones que cada estudiante haga en ese marco, es decir, la práctica a la que se arribe, depende del aporte concreto de cada disciplina tal como estos aportes derivaran del éxito de la propuesta integral.

Al considerar a lo multidisciplinario como condición para conformar el equipo, se apuesta al potencial de dicha metodología, a la integralidad del diseño de la propuesta en respuesta a esa necesidad insatisfecha que manifiesta la organización y que el 
equipo detecta, a la convergencia de distintos puntos de vista y herramientas disponibles de cada disciplina para abordar esta necesidad y a materializar a la práctica social como una solución concreta y útil.

\section{Las etapas transitadas por prácticas para la inclusión social} Las iniciativas de RSU en la FCE-UBA han evolucionado a lo largo del tiempo, al mismo tiempo que la extensión universitaria ha sido resignificada. En este sentido, es posible identificar etapas en la evolución del concepto de Responsabilidad Social Universitaria, así como en la relación entre los pilares fundamentales de docencia y extensión universitaria:

1) Antecedentes (2006-2010): en este primer período, las actividades de extensión estuvieron íntimamente vinculadas con la actividad principal de la FCE-UBA, esto es, la producción y extensión de saberes propios de las Ciencias Económicas. Tuvo por objetivo la generación de iniciativas que permitieran que la Universidad aportara a la comunidad desde sus saberes específicos. La RSU ha dado el marco adecuado para diseñar y llevar adelante actividades de extensión que han permitido establecer vínculos de solidaridad con la sociedad de la que forma parte la Casa de Altos Estudios.

2) Etapa 1 (2010-2014): a las iniciativas de extensión ya existentes - como el Museo de la Deuda Externa o el Centro Emprendedor GEN XXI- se le sumaron nuevas propuestas de RSU, desde el ámbito de la docencia. Este momento amplió los horizontes de la extensión universitaria, promoviendo la construcción de una universidad abierta y socialmente responsable a partir de innovaciones curriculares. El éxito creciente de diversas actividades de extensión permitió retroalimentar y permear la currícula, extendiendo las acciones a las carreras de grado a través de diversas propuestas hasta llegar a la concreción de una materia específica (PIS).

3) Etapa 2 (2014-2018): ha llegado, pues, el momento de la evaluación de resultados, alcance e impacto de las iniciativas de RSU y, en particular, del vínculo entre la docencia y la extensión universitaria. Es hora de diagnosticar: ¿qué hicimos hasta ahora? ¿Cuánto avanzamos? ¿Qué necesitamos mejorar?

Dada la implementación de una política universitaria en pos de lograr la integración curricular de la extensión, nos encontramos en la etapa de la elaboración del diagnóstico. Es preciso sistematizar los avances, incorporar los desafíos planteados tanto por los nuevos aportes teóricos de la disciplina y como por la experiencia práctica. Es momento de evolucionar, de diagnosticar desde una perspectiva cooperativa e inclusiva. Es hora de "pensar con otros" para pensarnos a nosotros mismos, reflexionar en torno al camino transitado y proyectar el camino por recorrer.

\section{El diagnóstico como insumo para asumir nuevos desafíos} En el marco de un análisis en torno al alcance e impacto de nuestras iniciativas de RSU, la gestión del conocimiento resulta fundamental. La misma se constituye a través de la articulación de un conjunto de métodos, procesos y herramientas que nos permiten crear, capturar, intercambiar, adaptar y poner en práctica el conocimiento tácito y explícito con el objetivo de lograr los resultados esperados y contribuir al impacto deseado de una forma eficiente. Asimismo, dicha información es estratégica y facilita la obtención y diseminación de conocimiento existente, la creación de nuevo conocimiento, la comunicación y colaboración entre las personas que lo poseen y el abordaje de potencialidades. De esta manera, la sistematización de la información recolectada de las experiencias en el marco de RSU nos permite reflexionar y brindar aportes teóricos para el desarrollo de futuras experiencias. Sistematizar es, entonces, el modo adecuado de comenzar a pensarnos, diagnosticar, reflexionar en torno a avances y desafíos. Para dicha tarea, el equipo de la Secretaría de Bienestar Estudiantil de la FCE desarrolla —entre otras - las siguientes herramientas: 1) El proceso de sistematización de la información recabada en las prácticas: se entiende como un proceso de creación de conocimiento a partir de la recopilación de información de calidad y pertinente, así como del análisis de la experiencia de intervención en una realidad determinada y la reflexión sobre esa práctica. Apunta a mejorar la práctica y la intervención, desde lo que ella misma nos enseña y, por otro lado, aspira a enriquecer, confrontar y modificar el conocimiento teórico actualmente existente, difundiéndolo y contribuyendo a convertirlo en una herramienta realmente útil para entender y transformar nuestra realidad. Reconstruir el proceso de la práctica, identificar sus elementos, clasificarlos y reordenarlos, posibilita que la experiencia se convierta en objeto de estudio e interpretación teórica. Sistematizar permite recuperar y visibilizar de manera ordenada y secuencial lo que ya se sabe sobre la experiencia; permite también descubrir nuevas aristas y revela nuevas variables que aún no estaban contempladas (y relacionarlas unas con otras).

2) El mapeo de organizaciones: ofrece una visión territorial delimitada a través de una herramienta gráfica. Vuelca la totalidad de la información referida al contacto con organizaciones a una herramienta que las compila, que las articula entre sí y potencia la práctica concreta. Por otro lado, localiza territorialmente las organizaciones con las que trabaja la Universidad y detecta experiencias que se multiplican, necesidades, falencias y éxitos, utilizando la variable territorial como eje de intervención. Es por ello que se generó la estrategia de un mapeo virtual de organizaciones, con el objetivo de difundir las actividades y programas de RSU que se encuentran en marcha en Facultades de Ciencias Económicas de universidades nacionales del país, así como las habilidades de cada organización participante. 


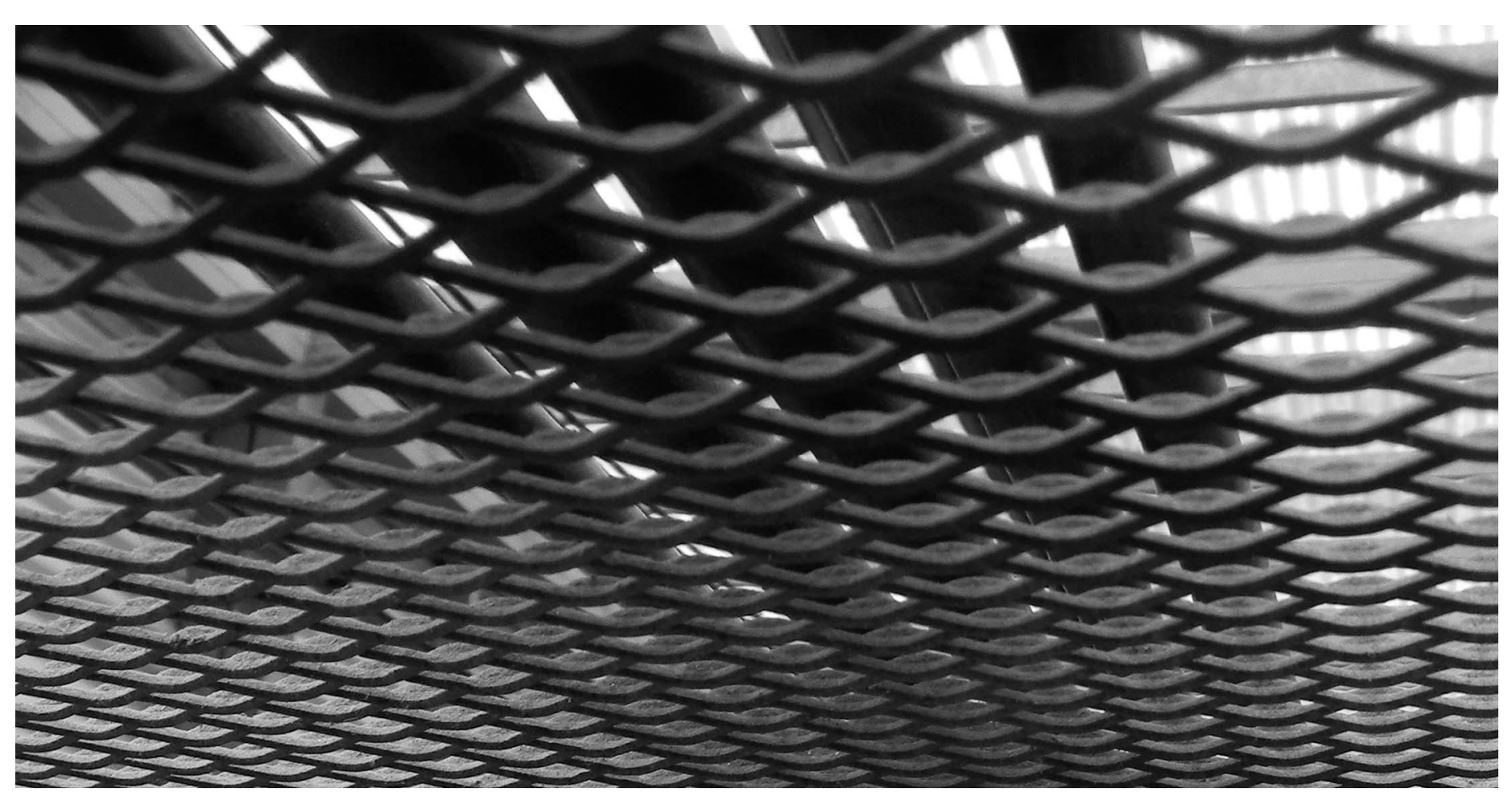

(c) Cecilia lucc

\section{Levantar la mirada}

PIS trabaja entendiendo que la planificación de una práctica social debe ser flexible, pues algunas eventualidades pueden exigir, en caso de surgir, una modificación en el curso de acción planificado. Nos referimos a cambios en la conformación de los equipos de estudiantes, ausencias que sobrecargan de tareas al resto de los integrantes, dificultades en la obtención de información acerca de la organización, eventos puntuales de la misma que demoran la respuesta o la concreción de los encuentros, dificultades para identificar el sector o actividad donde se va a realizar la práctica, modificaciones en los temas a tratar, entre otras.

Sin embargo, entendemos que el principal desafío radica en el hecho de que el esfuerzo focalizado hace que muchas veces la práctica solidaria no esté interconectada con instituciones $u$ organizaciones que trabajan en la misma problemática abordada, que atienden la misma necesidad pero desde otra perspectiva, con distinta metodología o recursos: en la posibilidad de la articulación y la labor compartida es precisamente donde está la llave para encontrar mejores respuestas a los problemas de la comunidad. El camino que actualmente transitamos, es decir, el camino de la evaluación de una política universitaria que sinergia la "docencia" con la "extensión", nos indica que para potenciar los logros ya alcanzados, debemos "levantar la mirada", darnos cuenta de que hay más personas queriendo lo mismo, superar la percepción de una actuación unilateral y avanzar en una mayor interrelación con los demás, para que eso redunde en beneficio colectivo.

La práctica y la articulación con las organizaciones hablan de una universidad relacionada indisoluble e inevitablemente con la comunidad. Dicho vínculo es crucial en un tiempo histórico donde el conocimiento ha adquirido un lugar central en el desarrollo: ello no es posible sin la labor compartida, sin el "hacer junto a otros", sin la noción de lo colaborativo, el trabajo en equipo, el enfoque sistémico, la visión compartida. Las posibilidades de los otros multiplican las nuestras.

\section{Referencias bibliográficas}

Drucker, P. (1968). La era de la discontinuidad. New York: Harper \& Row.

Saravia, F. (2009). Seminario de Integración y Aplicación en proyectos sociales. Buenos Aires: Universidad de Buenos Aires.

Saravia, F. y Escobar, J. (2010). Hacia una democracia socialmente responsable. Buenos Aires: Promoteo.

Tapia, M. N. (2015). La solidaridad como camino a la excelencia académica. Trabajo presentado en el Tercer Congreso Internacional de Responsabilidad Social. Buenos Aires. 